\title{
Examining the Efficiency of Current International Economic Sanctions Concerning Iran
}

\author{
FLAVIUS CABA-MARIA \\ Department of International Economic Relations \\ Bucharest University of Economic Studies \\ Piața Romană no.6, Bucharest \\ ROMANIA
}

\begin{abstract}
The study approaches the economic sanctions imposed on Iran. It comprises a history of sanctions, reviewing their typologies and application while focusing on the sanctions the United States enacted against Iran. In July 2015 a deal was struck, with the commitment of Iran to reduce significantly its advances in the nuclear programme in exchange for appeasement of the comprehensive sanctions regime. Nonetheless, the Trump administration proceeded to unilateral withdrawal from the deal in May 2018, thus extending the imposition of sanctions to a higher degree. As such, the paper tackles a long-standing dilemma whether sanctions do alter political responses and if so, their efficiency, based upon several factors regarded as important for the evaluation.
\end{abstract}

Key-words: coercion, sanctions, Iran, JCPoA, efficiency, failure

Received: August 2, 2020. Revised: January 26, 2021. Accepted: February 8, 2021. Published: February 15, 2021.

\section{Introduction}

Economic sanctions are known as a broadly used instrument with a view to coerce and limit certain actions in international relations. International actors have amplified their use in the past decades. Initially, sanctions were cutting ties between States, whereas they currently feature in the economic statecraft category and they imply a coercive aspect. There is a persistent dilemma regarding their efficiency. Strict answers have not been provided by the practice or theory. The $21^{\text {st }}$ century marked the era when they have been incorporated more often as part of foreign policy, going beyond finances and trade. Iran constitutes a perfect example for sanctions utilisation for over 40 years, coinciding with the establishment of the theocratic regime in 1979, although their effectiveness is disputable. Do we need sanctions to use them for an extended period if they are a successful instrument? Iran has a strenuous relationship with the United States of America/USA since almost the inception of the theocratic regime (1979), distorting Iran's activities (as the target country for sanctions) or forcing choices for costly options. The exception of these tensions happened during the time of striking the deal, namely the Joint Comprehensive Plan of Action/JCPoA. The nuclear agreement was signed on July, 14, 2015 by Iran and the format P5+1 (the permanent representatives of the United Nations Security Council, plus Germany). The deal was adopted three months later, on 18 October 2015, following a certain timeline. Importantly, the deal came into effect on January 16, 2016. This détente was accompanied by the Iranian promise to cut down its advances in the nuclear programme. It was a momentum for multilateral diplomacy.

The paper constructs a case study around Iran, since Tehran provides us with the example of prolonged use of sanctions, however, the analysis is focused on their situation subsequent to the USA withdrawal from the JCPoA (2018).

As a general rule for sanctions, there must be a coercive feature of the relation between the sender and the target. Therefore, in order to render sanctions effective, the sender needs a dominant position in connection to the target's resources, valuable assets. The paper assesses the diverse types of economic sanctions, sequences, although there are not definite answers concerning their performance in both economic and political terms (the two are to be separated only artificially). In fact, economic constraints can be used, unilaterally or not, to achieve political goals, just as economic 
goals can be achieved through the application of political measures, including military ones [16].

The economic sanctions operate somewhat complementarily to an all-embracing political decision, their impact being centred on target countries at the economic level, features observed for the Iranian case-study. However, the Iranian political structure met the challenges of the sanctions facing an economic collapse, while identifying methods to increase economic resilience and adaptation, which are discussed in the paper.

The analysis comprises literature review, theoretical aspects, highlighting seven factors considered significant for sanctions' examination. Finally, it interprets the present situation - Tehran and Washington tensioned relations to a high extent - concomitantly with exploring the efficiency of imposing a punitive regime.

\section{Literature review}

The paper is not tackling only a present-day concept, the notion of economic sanctions having known previous use. Hufbauer et al. identified 13 important situations for sanctions prior to 1990 [14]. In Ancient Athens, the Megaran decree constituted an incipient form of economic protectionism [24].

There is a chronological categorization of sanctions. Prior to 1989 sanctions were considered quite efficient, the target surrendering its economic policies or at least modifying its international relations' behaviour. This relative success can be explained by the fact bilateral ties were stronger than in present-day, sanctions having a direct effect on the target since the globalization process was in initial stages. The early studies identified stages of sanctions, such as: penalizing; acquiescence; weakening; signalling, and a symbolic representation for illustrative actions [17, p. 18].

In the decade after 1990, the scholarship commenced debating the efficiency of the use of sanctions. As a result, scholars have begun showing more interest in the evaluation of the economic costs. At this moment, the study of Hufbauer et al. [14] consolidates an evaluation model of the costs generated by the coercive acts, on behalf of both the sender and receiver. The outcome of the study is disappointing, furthermore Pape [18] concluded the rate of success is rather low - selecting five cases, with modest implications (see Table 1). Subsequently, Drezner [12] examined the United Nations/UN experience with sanctions, being an entity at the forefront of decisions regarding sanctions.

\begin{tabular}{|l|l|l|l|l|}
\hline No & $\begin{array}{c}\text { Year the } \\
\text { event } \\
\text { took } \\
\text { place }\end{array}$ & \multicolumn{2}{|c|}{ Participants } & \multicolumn{1}{|l|}{ Concrete action } \\
\hline 1. & 1933 & $\begin{array}{l}\text { The } \\
\text { United } \\
\text { Kingdo } \\
\text { m }\end{array}$ & USSR & $\begin{array}{l}\text { The release of six } \\
\text { prisoners by URSS }\end{array}$ \\
\hline 2. & 1975 & $\begin{array}{l}\text { USA/C } \\
\text { anada }\end{array}$ & $\begin{array}{l}\text { South } \\
\text { Korea }\end{array}$ & $\begin{array}{l}\text { Cancellation of a } \\
\text { factory plan by South } \\
\text { Korea }\end{array}$ \\
\hline 3. & 1979 & $\begin{array}{l}\text { Arab } \\
\text { League }\end{array}$ & Canada & $\begin{array}{l}\text { Canada cancelled the } \\
\text { plan of moving its } \\
\text { embassy }\end{array}$ \\
\hline 4. & 1987 & USA & $\begin{array}{l}\text { El Salvador } \\
\text { Ul to free three } \\
\text { detainees }\end{array}$ \\
\hline 5. & 1989 & India & Nepal & $\begin{array}{l}\text { Nepal eventually did } \\
\text { not proceed to } \\
\text { purchase weaponry } \\
\text { made by the RP } \\
\text { China }\end{array}$ \\
\hline
\end{tabular}

Table 1. Successful situations relating to economic sanctions prior to 1989

Author's version after Pape's researcher paper [18]; used in Caba-Maria\& Mușetescu [9] 
There are scholars who argue it is necessary to impose harsh measures for achieving the stated objectives of sanctions [19], [20], whereas others accept only partial accomplishment of targets [14].

With the evolvement of their applications, sanctions have been refined, renaming them as "smart sanctions" or "targeted sanctions". This development related to experience Cuba, Iran, Iraq, and North Korea as we witnessed a surging requirement to protect the civilian population from the deprivation of basic needs. Correspondingly, the prevailing economic sanctions imposed on North Korea or Iran by Western states provide inconclusive results related to their effectiveness in achieving the prevailing political goal [16].

In addition, there is a passage from state versus state sanctions (comprehensive regime) to tailored sanctions versus individuals or entities (targeted regime). The main entities that deal with sanctions - UN, European Union/EU, and the USA as a state-promoter of sanctions have adapted to this paradigm. The change is subsequent to the complaints of the 1990s when there were allegations sanctions act rather to the detriment of the civilians. In theory, target sanctions should keep sufferance for civilians to the minimum [1].

Globalization and interconnected commercial links render sanctions more difficult to apply in practice, as sanctioning products in one country may generate counter-effects for the sender [22]. The same author argues [22] that the current economic system equals to production networks that are connected globally and production processes that are disconnected. This understanding applies notably for developed economies, members in the Organization for Economic Cooperation and Development, thus requiring a certain degree of economic complexity.

Typology of sanctions varies, yet they need to encompass aspects of "economic coercion", depicting a softer version of the trade war, and vary in function of purpose and context. Baldwin [3] argued they feature only a limited depiction of the typology that concerns products that possess economic merit. Economic war has an overall effect on the economic structure until reaching military power. Economic combat seeks long-term goals, in comparison to economic sanctions that are conceived for immediate purposes. Economic incentives work with technology and know-how transfers, aiming to influence the target's actions. For Baldwin [3], trade wars question the whole paradigm of economic models/policies, which one could compare to the contemporary USA versus China economic thinking.
The study places sanctions under the framework of "economic statecraft". Thus, it operates with the concept understood as forcing a target to obey the sender's goals, under pinpointed intentions. It gives credit to the definition of sanctions focusing mainly on the coercive actions for obtaining modifications in the behavior of the target [7].

Barber [4] made a categorization for sanctions, as following: primary, secondary, and tertiary. Primary objectives aim at the government in the target country, whereas the secondary objectives approach assumptions and intentions established by the sender. At international level, tertiary sanctions are evaluated. The three enunciated types of sanctions are to be combined freely in order to meet targets.

When analyzing the objects of sanctions, one can notice a diversification of typologies, varying from boycotts, embargoes and sanctions of financial nature. The boycott restricts bringing in merchandise or any object with economic value from a target country, whereas the embargoes ban the exports (in a total or partial form) originating from the target. Financial sanctions deal with limitations on potential investments in a target country, restrictions regarding remittances and/or assets-freeze [10].

Mentioning the surge of liberalized trade in a globalized world, the entity promoting such principles, namely the World Trade Organisation/WTO views sanctions from the perspective of its dispute settlement mechanisms that could give rise to retaliatory actions [23]. Smeets also notes [22, p. 18] that economic sanctions are grounded in two articles of the WTO treaty "General Agreement on Trade in Services" (1995), namely Article XXI and Article XIV bis, for reasons of security, retaining an exceptional character.

With regards to the analysis of efficiency, the Peterson Institute (headquartered in Washington D.C., specializing in economics) collected a record (over 200 cases), yet it remarked that two in three cases fail to meet their goals [7], while the Targeted Sanctions Consortium/TSC on sanctions imposed by the UN also indicated a partial success. The respective study admitted sanctions have chances as many chances to fail like any other political tool. The same analysis [7] acknowledged seven elements for examining to efficiency of sanctions in use: calculating trade volumes that need to be significant preceding the enforcement of sanctions; the early onset of implementation becomes crucial; certain psychological features; the (un)democratic nature of 
the regime in the target country; the power of multilateral engagement; goals that are defined strictly and multi-factorial policies; and targeted sanctions are as likely to thrive as comprehensive ones. The present study takes into account each factor and assesses it in the case of economic sanctions imposed for Iran, constructing the core part of the analysis.

Despite the initial thoughts of effectiveness, sanctions do not provide us with a universal solution. As viewed by Caba-Maria \& Mușetescu [9] this area of study was not covered widely in literature, notably when you approach political structures that do not operate similarly to the Western world - for example, the Russian Federation, North Korea, Iran, Venezuela, and so on. Given this context, the paper aims to explain how economic sanctions work (or not) in the Iranian case (following the recent events for the precise purpose of this analysis), comprising their evolution and encompassing ongoing circumstances. The USA has long been the trendsetter of imposing economic sanctions on Iran pursuing governmental change having in mind Iranian acts deemed contrary to American policies. Furthermore, 2020 found the USA-Iranian tensions at a peak [5], resulting in more sanctions that did not alter Iranian viewpoints in public policies.

\section{Problem formulation and methodology used}

The study confides in a descriptive method taking into account various dimensions of economic sanctions, elaborate in the literature review part, mixing it with the qualitative method - examining various dimensions pertaining to the field of economic sanctions in the Iranian case, based upon a hypothesis that examines seven factors of measuring the success of sanctions. In terms of quantitative methods, the paper relies on data-based reviews, statistics, conclusive for the case-study. This analysis describes the typology of sanctions, as it is approached in the available scholarship. Sanctions do incorporate an economic dimension, not only coercive acts, thus policymakers take inputs originating in economic postulates [21]. This mutual relation cannot be broken apart for obvious reasons.

Some authors make the connections between the core elements of the WTO and the sanctions: the combat free trade versus restricted one. The main part of the study focuses on the seven factors that are meant to evaluate the efficiency of international sanctions, debating them in the Iranian case. The main question that surrounds sanctions is their efficacy. Hufbauer et al. rank among the pioneers that dealt with it in an interrogative manner [14]. Nonetheless, sanctions are widely encountered globally. When it comes to the case-study constructed - Iran - we encounter the varied typology of sanctions, being a country seriously targeted by sanctions, especially under the patronage of the USA. After the Second World War, Washington is a prime leader in enacting sanctions [10]. USA brought sanctions to the rank of state policy in the 1990s (imposing them in a consistent way to former Yugoslavia and Iraq, among other examples than Iran) - from the perspective of economic statecraft. Multilateral entities such as the $\mathrm{UN}$ or the EU have handled sanctions repeatedly in the past decades [32]. The concept has evolved; thus, one can notice its tuning (towards targeted/smart sanctions) since the sanctions are aimed to affect authority/public policies (of Iran) instead of citizens. However, the attainment of basic needs remains at least problematic in targeted countries. For instance, Iran suffers under the height of sanctions, as the USA administration promised (and ultimately enacted) to set in place a relentless coercive regime, comprising an extended system after the unilateral withdrawal from the nuclear agreement in 2018. Thus, the study debates the efficiency of sanctions in the case of a prolonged timeframe and comprehensive features. Who achieved its goals? Did Iran concede to the pressure of the USA or not? If not, what is the answer in case of failure?

\subsection{Seven factors for considering the efficiency of economic sanctions}

One should keep in mind that if a sanction fails to alter the target's behaviour, it does not amount to a total failure. Sanctions might succeed in achieving partial targets or managing to succeed in changing behaviours. In the example of Iran, one could notice the "promoter" state [10] - the USA - leading the trend-setting of sanctioning Iran (either by the lobby in the multilateral or region fora, and/or by exerting pressure at bilateral level). Under the Trump Administration of the USA, there was implemented a "maximum pressure" policy, a "zero-oil-export" enacted in Congress acts [28].

The study conceptualizes Biersteker \& van Bergeijk arguments for the Iranian case [7]. Accounting for the pre-sanctions trade: if trade volumes are not significant, the impact of the sanctions is not intense either. However, boycotting or embargoing products with high market value is likely to stir domino effects. According to Biersteker \& van Bergeijk, this aspect does not 
receive so much attention nowadays [7]. In the proposed thesis, US-Iran trade relations are quasiinexistent, however, the USA exerted pressure on potential traders with Iran, limiting Iran more. European partners of JCPoA would have liked to engage in bilateral trade, for example. As a result, in January 2019 we have France, the United Kingdom, and Germany creating a new mechanism, called the Instrument in Support of Trade Exchanges/INSTEX with the purpose to operationalize certain aspects of exchange trade with Iran, overpassing the US dollar restrictions, as a bypass to American coercive tools in terms of commerce with the Iranian side. The instrument mostly trades humanitarian goods from the medical and pharmaceutical sectors, allowing food products as well. It was agreed that Iran can bring: pistachios, carpets, and several agricultural products to Europe. Other European States, namely - Nordic Countries (Denmark, Norway, and Sweden), the Netherlands, and Belgium - joined the INSTEX at the end of 2019 [29]. Iran's response to the strenuous aspects generated by sanctions is one called "graduated pressure". Since the middle of 2019 there are looming threats concerning the eventual fracture of the JCPoA if Europeans do not add more advocacy in the favour of the deal [25]. The year 2020 meant more compromises for JCPoA and supplementary controversies to the level that the implementation of the agreement is in peril. However, might be the installation of a new Administration in White House that could revive matters and appease tensions.

The early onset of the sanctions matters. If the sanctions are longer in place, it allows additional time for the target to calibrate its economic system accordingly. For example, reallocation of labour division or reassessing economic priorities requires time. In addition, a large country such as Iran is characterized by a high elasticity of demand for imports, as it can be met relatively more easily from other suppliers: the same change (reduction) in the quantity imported will result in a lower price increase. Therefore, market distortions are expected to be lower [16]. Secondly, while adjusting to the new realities of sanctions, economic performance can enhance. According to Biersteker and van Bergeijk [7], the potential sanction damage hits the highest before the adjustments set in. Iran is an example of the economy under adaptation under the duress of sanctions. The main reason why it has not collapsed is Iran's diverse economic base and its high degree of resilience and adaptability. A collapse remains very unlikely. Currently, one could observe that even the Iranian Gross Domestic Product/GDP is rounding after three years from the 2018 moment (delayed by Covid-19 pandemic). The Iranian economy has experienced stagflation for the past two years. It is even likely that by 2021 the economy will recover its losses (Figure 1) circumstances being complicated by the Covid-19 pandemic, however still doable. In addition, Iran is much less exposed to oil market fluctuation than another oil producer States, as lately it has had limitations on oil (and derived industry) exports, exactly because of the sanctions regime.

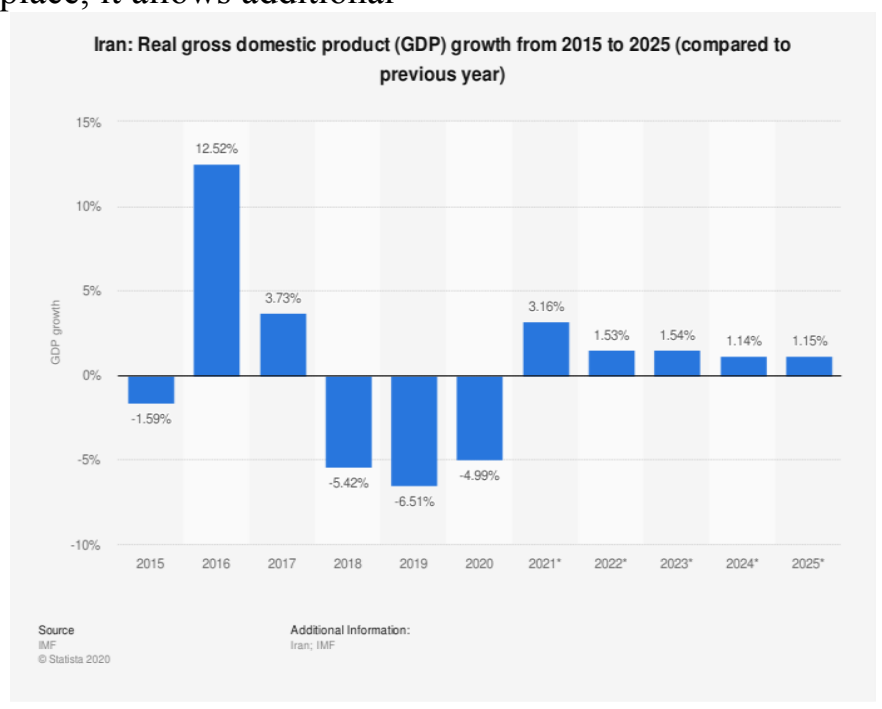

Figure 1. Iran's growth projections [27]

The element of surprise: sanctions are most effective when coming by surprise and have the potential of a real menace. In the situation of Iran, sanctions are not a stranger element, given such a long horizon of application. Even though the 2018 withdrawal of the USA from the JCPoA was quite 
abrupt, the Iranian leadership always perceived the US as a foe and tried not to act taken by surprise.

The effectiveness of democratic checks and balances: it results in sanctions encountering stronger adversity in democracies in comparison to autocracies. Authoritarian regime being mostly centralized can distribute shares and cover losses in a manner that can lead to the endorsement of autocracy. Iran has indeed an authoritative regime, yet it endowed with checks and balances. Yet, the opposition's political effectiveness is far from that of the regime. Thus, the sanctions have not dismantled the governmental apparatus.

If sanctions are having a pronounced multilateral character, the target country has fewer chances to escape their effectiveness. Moreover, multilateral sanctions, including here regional organizations imposing sanctions on members (rather than on non-members) benefit from more legitimacy, according to Biersteker \& van Bergeijk [7]. One should note we still lack the ground to reach a consensus on sanctions' efficiency in a comprehensive manner. An in-depth review was made for TSC databases [8]. It indicated there is a gradual preference for tailor-made sanctions. The UN sanctions most often come in a package with diplomatic endeavours (97\%), peacekeeping deployment $(62 \%)$ and a looming threat for the use of force $(62 \%)$ [13]. Currently, unilateral and regional sanctions precede UN action (70\%). This review of 2016 concluded sanctions work better when combined. It argued the more successful cases comprise bans regarding weaponry, restrictions regarding travel of certain persons, and freezing assets [8]. Iran received such a comprehensive set of sanctions from several entities, including the UN and the EU that should be effective according to these criteria. Nonetheless, in combination with other factors, it does not seem to have the same impact.

The simultaneous application of other policy instruments: referring to international courts, regional sanctions, and other measures, tend to adjust the target country's behaviour more, from Biersteker \& van Bergeijk point of view [7]. Furthermore, the authors argue that applying sanctions to a whole territory is more effective than singling out only parts of the country. Definitely, one could attest that Iran is affected as a whole, and even when it operates abroad. Moreover, it faced different related measures, such as referral to international court - as it happened in the litigation of USA against Iran (1980) at the International Court of Justice.
The aforementioned study implies that targeted sanctions are not so different from a comprehensive set of sanctions. In other words, it was reported [7, p. 27] that when examining a cluster, one could detect an average of $22 \%$ performance rate in the instance of 63 cases of targeted sanctions enacted by the UN. In the same report, the data of Peterson Institute pinpointed an overall efficiency rate of $33 \%$ for all types of sanctions (including both comprehensive and targeted ones). Targeted sanctions are in use in Iran, specifically for the avoidance of civilian punishment, yet the Iranian population suffers otherwise there is no need to implement alternative humanitarian ways. Iran is gradually reaching a saturation point, reiterating that up to mid-2019, it respected the terms of the nuclear agreement, fact confirmed during the inspections of the International Atomic Energy Agency/IAEA [26] and of other EU official representatives. The gradual disappointment with the enforcement of the deal would mean more compromise on commitments. The JCPoA agreement weakened, turning Iran to alternatives, leading to the creation (post-prolonged diplomatic talks) of the Swiss Humanitarian Trade Arrangement/SHTA [30]. The first attempts of SHTA took place in February 2020, bearing in mind that what falls under relief supplies, hereby aliments, medicines and other similar categories receive an exemption from the punitive measures of sanctions. The year of 2020 coincides with the Covid-19 pandemic that opened the doors for cooperation in the region, for example with the United Arab Emirates and Qatar. Iran was among the worst affected states by Covid-19 in the Middle East, crisis exacerbated by the slow acquisition of medical equipment and kits in the wake of multiple sanctions. Medical equipment and other supplies were delivered to Iran with military airplanes from Dubai [31]. Thus, in the circumstance of Iran, despite the arguments invoked by the USA leadership - punishing the Iranian decision-makers, the population feels the effect of the sanctions' regime, not making a big difference between targeted and comprehensive sanctions.

As a conclusion over the seven hypotheses is that in the case of Iran, we can verify the multilateral nature of sanctions applied and the simultaneous imposition of numerous policy instruments, all aimed to modify Iran's behaviour. Iran has certainly been the recipient of a combined strategy for sanctions, coming via multilateral direction, mainly under the guidance of the USA. Although the conditions are not favourable, the Iranian economy is still standing, even with 
prospects of recovery, in a two-three year's span post-2018 (rather three years, as the Covid-19 pandemic produced a global recession).

\section{Problem discussion and solutions}

One should note that the sender country shall evaluate the scale of values for certain target country with the purpose to see what could be most affected by sanctions. For instance, Iran and its long-term reliability on oil revenues represented a vulnerability. Therefore, a bulk of sanctions enacted by both the EU and the USA targeted the core of the Iranian oil industry-meaning it was a calculation based upon financial and commercial patterns of Iran. Iran was outcast from the oil market with the restriction on hydrocarbon products. At the EU level, one of the punitive acts was the exclusion of Iran from the Society for Worldwide Interbank Financial Telecommunications/SWIFT, the very system in charge with the flows of world finances. This action came accompanied by significant pressure, symbolising further restrictions in terms of payments and trade [6]. However, the measures were already in place at the moment of US withdrawal from the JCPoA. As a result, for the seven factors analysis, these aspects are not important as much.

Dizaji \& van Bergeijk drew conclusions about a chronological order for sanctions: the effects are most visible in the earliest phase after the enforcement (probably during the first two years), waning after a while (maybe in six-seven years), due to economic adaptation and adjustments [11]. The International Monetary Fund (IMF) expects Iran's economy to return to growth in 2021 - perhaps with roughly 3\% [27]. This comes after the Covid-19 pandemic inflicted great harm on the global economy. However, the economic dwindling did not seem to change the course of political actions/leadership of Iran. In fact, politicians invoked sanctions as a reason to explain economic hardship [22], in addition to the lack of access to medication and supplies to tackle the sanitary crisis. Thus, Iran faced with the "maximum pressure" policy conducted by the USA was unable to reach its potential. Nonetheless, looking at indicators of a dwindling GDP as an effect of restricted oil revenues resulting from restrictions of export, exclusion from the global payment system/SWIFT (with a concrete effect upon economic flows), it appears sanctions are in full motion.

Theoretically, states targeted by sanctions maintain constant difficulties in reaching supplies, supposing they need goods they are exempted from [22]. Nonetheless, in the situation of Iran, we observe mechanisms of resilience. Moreover, despite being among the highest affected by Covid19 in the Middle East, the structure and political apparatus did not fall down, neither disintegrate.

One could tell also that globalization means the production chains and markets are connected together, so you can not eliminate one country from this network. As a result, Iran being singled out by the USA and its collaborators shifted towards European partners and mostly towards Asia. Iran leaders faced material restrictions, yet they maintain the functionality of the state and rearrange priorities. Therefore, one shall observe that leaders face challenges in the allocation of resources [15]. Iran has already carried out economic reforms in the past years, in order to maintain capabilities in the economic fields, turning away from the effect of sanctions. Tehran is still surviving in the form of a theocratic regime despite the longest sanctions' regime and by the means of Dizaji \& van Bergeijk study [11], the economic alterations could mean in six years effects are attenuated. It results in reshuffling priorities and resources, whereas the opposite did not provide any credible alterable. For instance, the assessment of the seven factors conducted to the conclusion that the governmental structure is maintained control on five out the seven factors, which Biersteker \& van Bergeijk [7] use as parameters for sanctions' efficiency.

\section{Conclusion}

Iran makes the case for a study debating economic sanctions, since probably stands for the typical state under a strict comprehensive set of sanctions (also known as the "maximum pressure" policy under the President Trump administration), the sanctions extending for a duration of over forty years. The study enables us to conclude that economic sanctions are not a purely economic concept, their effects can touch upon civilian lives and ultimately aim to affect political decisions.

Iran has been the recipient of sanctions unilaterally (via the USA) or internationally (UN, EU), representing strong impediments for the economic growth of Iran. The sanctions of a more recent nature in connection to the development of the nuclear programme have produced a visible impact [29]. These ones reach out to numerous fields, including the military and strategic sectors, the banking and financial sector. The sanctions saw Iran reducing the dimensions of its economic flows, a sharp decline in the currency and problems with exports - its oil industry being most affected [2].

Iran is a long-standing recipient of sanctions, however in 2015 reached a deal over its 
contested nuclear programme. The promise of easing the sanctions regime was already boosting the economy, on the contrary, their re-enactment post-2018 strains everyday life, ever much so in the outbreak of the coronavirus pandemic.

Recent scholarship and practice focusing on economic sanctions highlights the current application of targeted/smart sanctions, constituting supposedly a customized instrument, protecting the civilians from deprival of needs (at least in theory). Furthermore, with several attempts in order to calibrate the concept of sanctions, smart sanctions are considered a step forward. However, they constitute a complementary tool to other methods/instruments, reviewed poorly in some specific examination. For instance, the mere fact that Iran went through diplomatic talks with other partners, including Switzerland for SHTA, in order to be able to bring medication and relief supplies to its country indicate how difficult is to cope with sanctions in daily life, although targeted sanctions are in use.

The paper debates how efficient (or not) the sanctions are in the case of Iran. After examining the proposed seven factors, the paper reaches the conclusion they are not. There is a gap in the literature review, notably when one thinks of alternatives if sanctions do not meet their goals. For the purpose of further research, one should take into account examining the future policies of the US under a new Administration and the consequences subsequent to the unfolding Covid-19 pandemic.

To sum up, it is undeniable there is an immense pressure of sanctions looming over Iran's economy, being translated into concrete cutbacks [28]. Moreover, the USA policy swayed away European and even Asian partners, notably given the sanctions in the banking (including international payments) domain, making previous efforts for diplomacy futile. Dizaji \& van Bergeijk acknowledged sanctions shock the economy mostly in the first two years, aspect that matches IMF predictions for 2021 [11]. Iran has managed to identify the means to become resilient, with the help of several economic reforms. In fact, the response to the "maximum pressure" policy is the "maximum resistance" policy. The most strenuous aspect is represented by international payment flows and the way the USA pressures others in avoiding work and trade with Iran, against all odds. The Swiss channel together with INSTEX have been created in order to respond to civilian needs, yet they are difficult to be assessed economically, since they target a limited span of products and function narrowly. Sanctions theory lacks the response in terms of defining success rate for sanctions. If they are meant to modify political responses, in the case of Iran, its leadership is still standing, in spite of adversities. Moreover, they are managing to keep under control five out of the seven factors examined in the present study. De facto, the Iranian government proclaimed in mid-2020 that the American administration admits the vulnerabilities of its "maximum pressure" policy [5].

\section{References:}

[1] Amuzegar, Jahangir, Iran's fourth plan: A partial assessment, Middle East Policy, vol. 17, no.4, 2010, pp.114-130.

[2] Arnold, Aaron. Current State of Global Sanctions against Iran. Belfer Center for Science and International Affairs, March 2015, Accessed at

https://www.belfercenter.org/publication/cur rent-state-global-sanctions-against-iran.

[3] Baldwin, David A. Economic Statecraft: New Edition. New Jersey: Princeton University Press, September 2020.

[4] Barber, James, Economic Sanctions as a Policy Instrument, International Affairs, vol. 55, no.3, 1979, pp.367-384.

[5] Barzegar, Kayhan, The hard chess puzzle: Trump's 'Maximum pressure' versus Iran's 'Maximum resistance', Al Jazeera Center for Studies, June 2020, Accessed at https://studies.aljazeera.net/en/reports/hardchess-puzzle-trump $\% \mathrm{E} 2 \% 80 \% 99 \mathrm{~s}-$ $\%$ E2\%80\%98maximumpressure $\% \mathrm{E} 2 \% 80 \% 99$-versusiran $\% \mathrm{E} 2 \% 80 \% 99 \mathrm{~s}-\% \mathrm{E} 2 \% 80 \% 98$ maximumresistance $\% \mathrm{E} 2 \% 80 \% 99$.

[6] Bazoobandi, Sara. Sanctions against Iran: Winners and Losers. In Dreyer, Iana and Luengo-Cabrera, Jose. On target? EU sanctions as security policy tools - Issue report 25 (pp. 57-65). EU Institute for Security Studies, Normandy: Conde-surNoireau, 2015.

[7] Biersteker, Thomas \& van Bergeijk, Peter A.G. How and When Do Sanctions Work? The Evidence. In Dreyer, Iana and LuengoCabrera, Jose. On target? EU sanctions as security policy tools - Issue report 25 (pp. 17-28), EU Institute for Security Studies, Normandy: Conde-sur-Noireau, 2015.

[8] Biersteker, Thomas J., Tourinho, Marcos, \& Eckert, Sue E, The Effectiveness of United Nations Targeted Sanctions. Targeted Sanctions, 2016, pp. 220-247. 
[9] Caba-Maria, Flavius \& Mușetescu, Radu, The impact of international economic sanctions on national economies. The Islamic Republic of Iran - a case in point, Proceedings of the 14th International Conference on Business Excellence 2020, pp. 1014-1023. DOI: 10.2478/picbe-20200096, ISSN 2558-9652.

[10] Caruso, Raul, The Impact of International Economic Sanctions on Trade - an Empirical Analysis, 2003, Available at SSRN: https://ssrn.com/abstract $=895841$ or http://dx.doi.org/10.2139/ssrn.895841.

[11] Dizaji, Sajjad Faraji, \& van Bergeijk, Peter A. Potential Early Phase Success and Ultimate Failure of Economic Sanctions. Journal of Peace Research, vol.50, no.6, 2013, pp.721736.

[12] Drezner, Daniel W. Bargaining, Enforcement, and Multilateral Sanctions: When is Cooperation Counterproductive? International Organization, vol. 54, no.1, 2000, pp.73-102.

[13] Eckert, Sue E. The Evolution and Effectiveness of UN Targeted Sanctions. In Larissa van den Herik (edited), Research Handbook on UN Sanctions and International Law, 2017, pp. 52-70.

[14] Hufbauer, Gary Clyde., Schott, Jeffrey J. \& Elliott, Kimberly Ann, Economic sanctions reconsidered: History and current policy. Washington: Peterson Institute for International Economics, 1990.

[15] Jones, Lee, FPC Briefing: How Do International Economic Sanctions (Not) Work?, 2015, Accessed at: https://www.files.ethz.ch/isn/194802/1708.p df.

[16] Miron, D., Cojanu, V. (eds.), Burnete, S., Volintiru, C., Dorobat, C.E, Comerț internațional. Volumul I-Specializarea țărilor şi sistemul comercial multilateral. București: Editura ASE, 2013.

[17] Nincic, Miroslav, \& Wallensteen, Peter Dilemmas of Economic Coercion: Sanctions in World Politics. Westport: Praeger Publishers, 1983.

[18] Pape, Robert A., Why Economic Sanctions Do Not Work. International Security, vol.22, no.2, 1997, pp. 90-136. Accessed at https://web.stanford.edu/class/ips216/Readi ngs/pape_97\%20(jstor).pdf.

[19] Pape, Robert A., Why Economic Sanctions Still Do Not Work. International Security, vol.23, no.1, 1998, pp.66-77.
[20] Rodman, Kenneth A, Sanctions Beyond Borders: Multinational Corporations and U.S. Economic Statecraft. Maryland: Rowman \& Littlefield, 2001.

[21] Simons, Geoff, Imposing Economic Sanctions: Legal Remedy or Genocidal Tool?. London: Pluto Press, 1999.

[22] Smeets, Maarten. Can Economic Sanctions Be Effective? WTO Working Papers. No. ERSD-2018-03, World Trade Organization (WTO), Geneva, 1998, Accessed at https://www.wto.org/english/res_e/reser_e/e rsd201803_e.pdf.

[23] Smeets, Maarten. Conflicting Goals: Economic Sanctions and the WTO. Global Policy Dialogue, vol.2, no.3, 2000.

[24] Thucydides, Translated by Rex Warner. History of the Peloponnesian War. New York: Penguin, 1997.

[25] Germany fights to salvage Iran nuclear deal as deadline looms, June 10 2019, Accessed at https://www.dw.com/en/germany-fights-tosalvage-iran-nuclear-deal-as-deadlinelooms/a-49108530.

[26] IAEA: Joint Statement by the Director General of the IAEA and the Vice-President of the Islamic Republic of Iran and Head of the AEOI, August 2020, Accessed at https://www.iaea.org/newscenter/pressreleas es/joint-statement-by-the-director-generalof-the-iaea-and-the-vice-president-of-theislamic-republic-of-iran-and-head-of-theaeoi.

[27] IMF Predicts Iran Economy to Return to Growth in 2021, 14 October 2020, Financial Tribune. Accessed at:

https://financialtribune.com/articles/domesti c-economy/105727/imf-predicts-iraneconomy-to-return-to-growth-in2021?_cf_chl_jschl_tk_ $=6 \mathrm{~d} 15 \mathrm{fa} 7 \mathrm{f} 67 \mathrm{f} 4 \mathrm{fc}$ 8f55198a 1 c $2554901 \bar{f} 99 \overline{6 b} 16 a 6-$ 1611748964-0-

AavBYHjWanVEXupKpr8ycNvcoXQVKt GQ0UxC3Xc5SRMYd4u802oVvM-

KASKNCmGIcFzgnHiKJMiWxIFqj85_Y WqGrSglKeU8Ib2RBfzi4LOb8huwzEdYN GHxt2nj51wMPsvir2KMrBNKLLA2dmQg YW0r3tD0WphQzaoDVstPfOcbzmPt7TKA HA7wMHh6UJ5ndupCZLOdhOAlwCgoV YT-

z2mJZXzkqvslFcqfMX2mhmCFPVgTgHM IXrWauGGyOtHdtZDdFuMBzTCz6QQ8f7 QOVghCWMMil6R58Mq4zOxtE7EYiOH ZGJJH3wAZW8N7xBm_cFvEm_V0s2tFrJ DMdze5HBU3OD7mb5jfTBS13SQFwlL- 
X.

ssSalDxOkwhcUah9XAiNz2--uthrvWYR7-

[28] Six charts that show how hard US sanctions have hit Iran, 9 December 2019, Accessed at https://www.bbc.com/news/worldmiddle-east-48119109.

[29] Six European Countries Join INSTEX Mechanism for Iran Trade, 1 December 2019, Accessed at https://www.bourseandbazaar.com/news1/2019/12/1/six-european-countries-joininstex-mechanism-for-iran-trade.

[30] Switzerland takes humanitarian strategy toward Iran, 4 February 2020, Accessed at
FWkPRf765dXsCXqBUTBH08m0FMUfo https://en.irna.ir/news/83660241/Switzerlan d-takes-humanitarian-strategy-toward-IranEmbassy.

[31] UAE facilitates WHO's medical supplies delivery to Iran, 2 March 2020, Accessed at https://gulfnews.com/photos/news/uaefacilitates-whos-medical-supplies-deliveryto-iran-1.1583161449047.

[32] What Are Economic Sanctions?,12 August 2019, Accessed at https://www.cfr.org/backgrounder/what-areeconomic-sanctions.

\section{Creative Commons Attribution License 4.0 (Attribution 4.0 International, CC BY 4.0)}

This article is published under the terms of the Creative Commons Attribution License 4.0

https://creativecommons.org/licenses/by/4.0/deed.en_US 